$\frac{314}{10 / 2410} T=5$

SAND80-0475

Unlimited Release

UC-60

\title{
Torque Ripple in a Darrieus, Vertical Axis Wind Turbine
}

Robert C. Reuter, Jr

Prepared by Sandia Laboratories, Albuquerque, New Mexico 87185 and I ivermore, California 04550 for the United Slales Department of Energy under Contract DE-AC04-76DP00789

September 1980

\section{Sandia National Laboratories}




\section{DISCLAIMER}

This report was prepared as an account of work sponsored by an agency of the United States Government. Neither the United States Government nor any agency Thereof, nor any of their employees, makes any warranty, express or implied, or assumes any legal liability or responsibility for the accuracy, completeness, or usefulness of any information, apparatus, product, or process disclosed, or represents that its use would not infringe privately owned rights. Reference herein to any specific commercial product, process, or service by trade name, trademark, manufacturer, or otherwise does not necessarily constitute or imply its endorsement, recommendation, or favoring by the United States Government or any agency thereof. The views and opinions of authors expressed herein do not necessarily state or reflect those of the United States Government or any agency thereof. 


\section{DISCLAIMER}

Portions of this document may be illegible in electronic image products. Images are produced from the best available original document. 
Issued by Sandia Laboratories, operated for the United States Department of Energy by Sandia Corporation.

\section{NOTICE}

This report was prepared as an account of work sponsored by the United States Government. Neither the United States nor the Department of Energy, nor any of their employees, nor any of their contractors, subcontractors, or their employees, makes any warranty, express or implied, or assumes any legal liability or responsibility for the accuracy, completeness or usefulness of any information, apparatus, product or process disclosed, or represents that its use would not infringe privately owned rights.

$S F 1004-D F(11-77)$

Printed in the United States of America Available from:

National Technical Information Service

U. S. Department of Commerce

5285 Port Royal Road

Sprinqfield, VA 22161

NTIS Price Codes

Printed Copy $\$ 6.00$; Microfiche: AOI 


\section{PAGES 1 to 2 WERE INTENTIONALLY LEFT BLANK}


SAND80-0475

Unlimited Release

Printed September 1980

TORQUE RIPPLE IN A DARRIEUS, VERTICAL AXIS WIND TURBINE

Robert C: Reuter, Jr. Applied Mechanics Division III, 5523

Sandia National Laboratories

Albuquerque, New Mexico 87185

\section{ABSTRACT}

Interaction between a steady wind and a rotating, Darrieus, vertical axis wind turbine produces time periodic aerodynamic loads which cause time dependent torque variations, referred to as torque ripple, to occur in the mechanical link between the turbine and the electrical generator. There is concern for the effect of tórque ripple upon fatigue life of drive train components and upon power quality. An analytical solution characterizing the phenomenon of torque ripple has been obtained which is based upon a Fourier expansion of the time dependent features of the problem. Numerical results for torque ripple, some experimental data, determinatioin of acceptable levels and methods of controlling $1 t$, are presented and discussed.

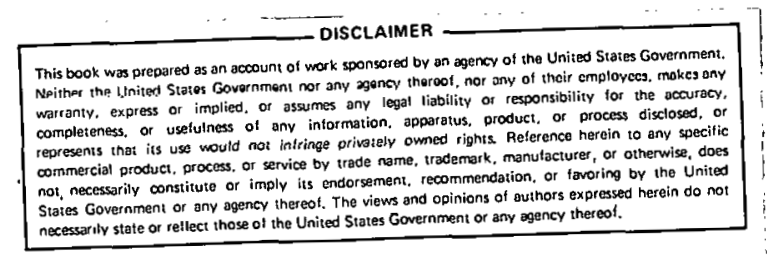


$\underline{\text { Page }}$

INTRODUCTION - - - - - - - - - - - 7

THE TORQUE RIPPLE MODEL - - - - - - - - 9

NUMERICAL RESULTS AND ALLOWABLE LEVELS - - - - - 15

CONTROL OF TORQUE RIPPLE - $\ldots$ - $\ldots$ - $\ldots$

CONCLUSIONS AND RECOMMENDATIONS - - - - - - - 25

ACKNOWLEDGEMENT - - - - - - - - - - - 27

REFERENCES - - - - - - - - - - - - 27

\section{ILLUSTRATIONS}

Figure

1 DOE/Sandia 17-meter, $60 \mathrm{~kW}$, Darrieus vertical axis wind turbine located

in Albuquerque, New Mexico

2 Applied torque versus azimuth position for one turbine revolution when $\lambda=5.0$

3 Applied torque versus azimuth position for one turbine revolutinn when $\lambda-2.0$

4 Schematic of turbine drive train components and nomenclature

5 Torque ripple versus tip speed ratio for the DOE/Sandia research turbine operating at 50.6 RPM.

6 Allowable values of torque ripple (expressed as a $\&$ of mean torque) based on infinite life of drive train components

7 Torque ripple (expressed as a $\frac{8}{8}$ mean torque) versus tip speed ratio for various values of low speed drive train stiffness

8 Torque ripple (expressed as a $\frac{\circ}{8}$ of mean torque) versus turbine operating speed for various values of low speed drive train stiffness 


\section{INTRODUCTION}

In a utility grid application, power gathered from the wind by a Darrieus, vertical axis wind turbine (VAWT), Fig. 1, operating synchronously, is in the form of mechanical torque at a specified rotational speed. Interaction of the rotating blades with the incident wind causes a time periodicity in the net torque acting on the turbine, which is obtained by integrating torque producing aerodynamic loads over all blades present. Under the ideal conditions of a steady wind from a fixed direction, the applied torque may be viewed as a deterministic oscillation called torque ripple, (which may contain many harmonics) superimposed on a steady, mean torque, which is relatable to overall turbine performance. Depending upon turbine operating conditions (such as wind speed and turbine RPM) and upon drive train characteristics (such as component inertia properties and torsional rigidities, gear ratios and generator slip) the magnitude of the oscillations may be either amplified or attenuated at various locations along the drive train. In view of extended component fatigue life and high power quality requirements, attenuation of torque ripple to acceptable levels is highly desirable.

Recognition of the torque ripple problem and its consequences, and attempts to characterize it analytically and demonstrate control over it are not new ${ }^{1,2}$. Two of the assumptions upon which early analytical work on torque ripple in VAWT systems was based ${ }^{l}$ are as follows: 1. The wind is steady and from a fixed direction, and 2. The net torque applied to the turbine is a simple harmonic function of time. Models based on these assumptions captured torque ripple behavior trends as parameters were changed ${ }^{l}$ and permitted at least initial insights toward understanding the problem. 


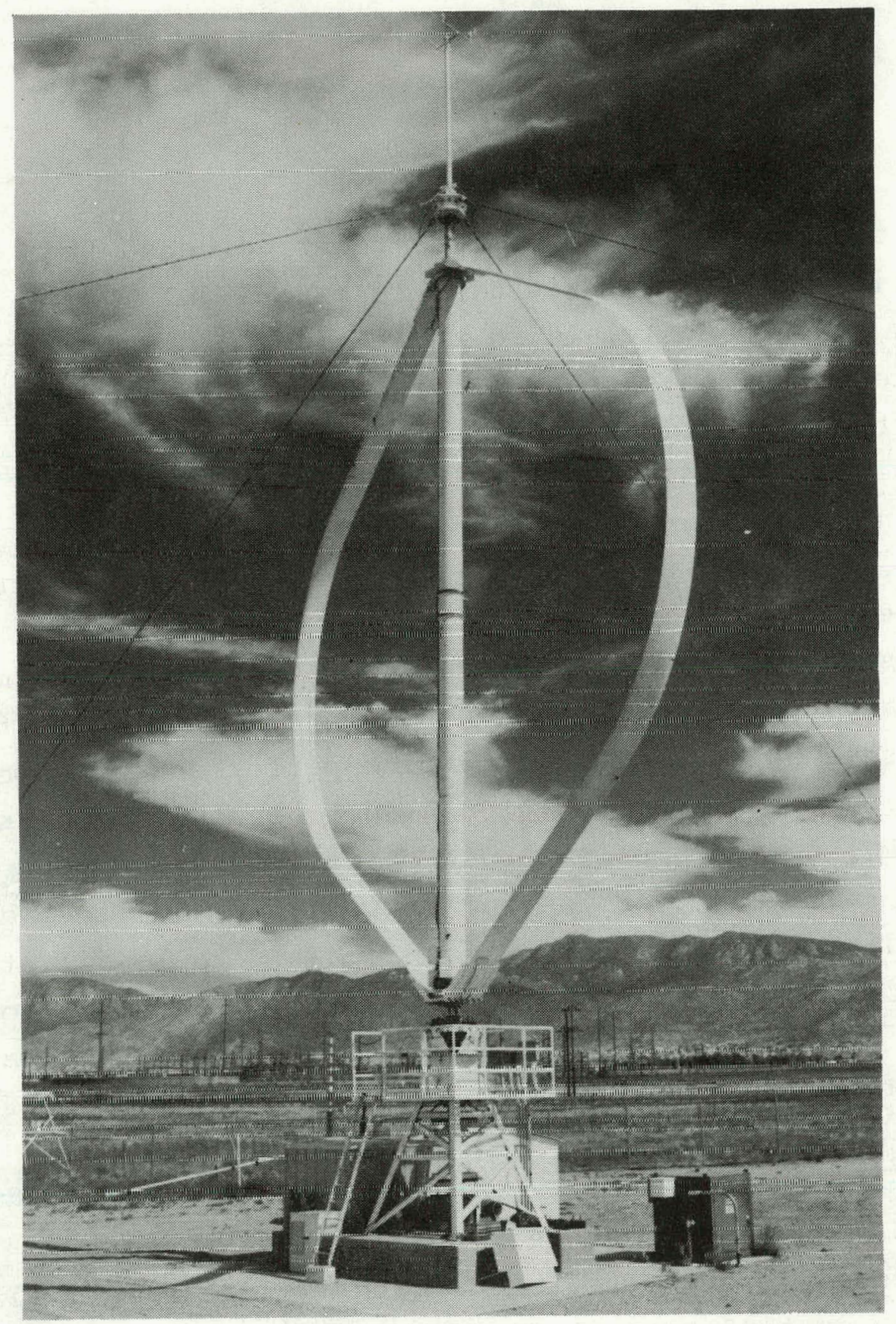

'igure 1. DOE/Sandia 17-meter, 60 KW, Darrieus, vertical axis wind turbine located in Albuquerque, New Mexico.

However, recent aerodynamic models ${ }^{3}$, from which come the magnitude and time dependence of the net aerodynamic torque applied to the turbine, demonstrate that the assumption of a simple harmonic form for the applied torque is not always 
justified. Asymmetries in the upwind and downwind aerodynamics $^{3}$, and the temporal influence of stall at high wind speeds, (a previously known result) ${ }^{4}$, cause multiple harmonics to appear in the applied torque, even for a fixed wind. By using a Fourier expansion of the time dependent characteristics of the torque ripple problem, a general solution has been obtained which permits full representation of the consequences of upwind and downwind aerodynamnic. asymmetries and blade stall. This approach, along with numerical results, a limited amount of data correlation, and a discussion of how acceptable torque ripple levels are determined and achieved, is presented. With appropriate modifications, this analysis may be used to study torque ripple in horizontal axis and other vertical axis wind energy systems.

THE TORQUE RIPPLE MODEL

A typical VAWT drive train consists of the turbine rotor (blades and rotating tower), a transmission and a generator, connected in series by various torque transmitting shafts and couplings. Additional components may be present depending upon the specific turbine design, purpose and installation. For example, the DOE/Sandia 17 -meter research turbine ${ }^{5}$ located in Albuquerque, NM, Fig, l, has a secondary gear ratio change capability in the form of interchangeable pulleys and a timing belt, located between the transmission (which has a fixed gear ratio) and the generator. This feature permits incremental changes in the turbine operating speed and allows field evaluation of aerodynamic, structural and system performance, in a synchronous mode, under a variety of operaliny conditions. "Operating conditions" refers collectively to combinations of incident wind velocity and turbine operating speed. A popular parameter characterizing operating conditions 
is tip speed ratio, $\lambda$, which is equal to maximum blade speed, $\mathrm{R}_{\mathrm{MAX}} \Omega$, divided by incident wind speed, $\mathrm{V}$. When $\lambda \geq 3.5$ the simple harmonic representation of applied torque and drive train response is justified ${ }^{l, 3,4}$, as seen in Fig. 2.

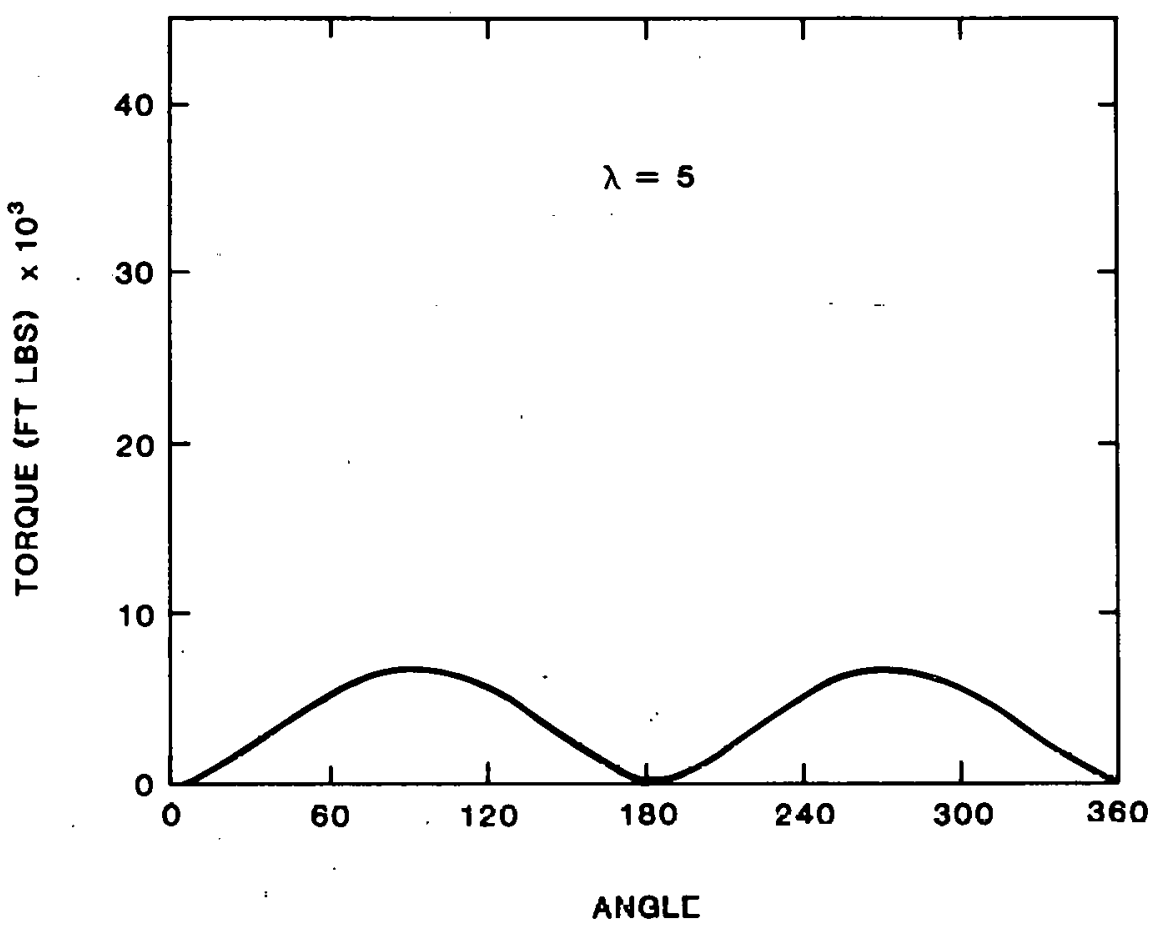

Figure 2. Applied torque versus azimuth pusition for one turbine revolution when $\lambda=5.0$

However, when $\lambda \leq 3.5$, blade stall effects and upwind and downwind aerodynamic asymmetries become strong 3,4 , thus compelling a Fourier expansion of torque ripple time characteristics, see Fig. 3. Since peak turbine power and, therefore, peak mean torque occurs at a tip speed ratio in the range of 1.0 to $3.0,5$, it is essential that dynamic behavior of the turbine be well understood for low values of $\lambda$.

The torque ripple model consists of three essential elements. The first is a simplified, physical representation of the important characteristics of the entire drive train for 


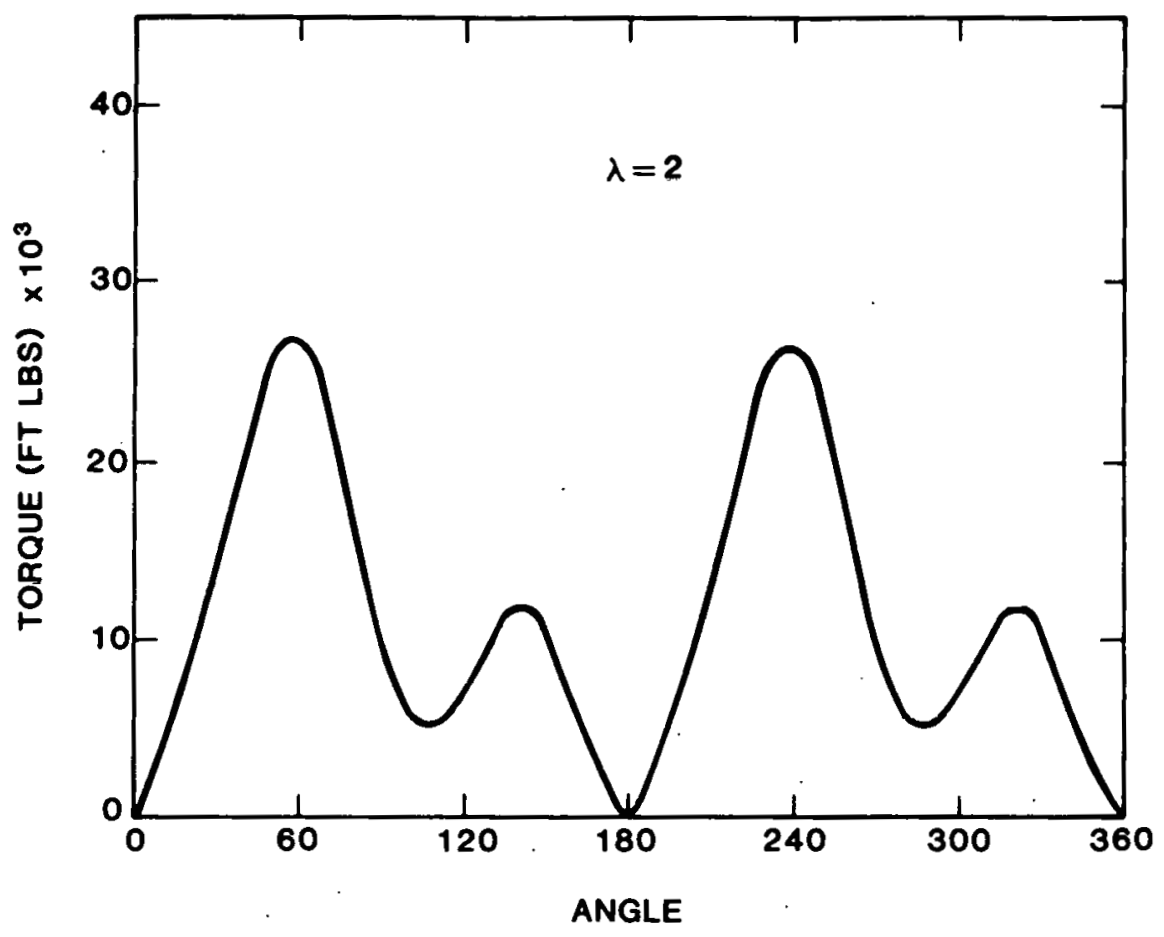

Figure 3. Applied torque versus azimuth position for one turbine revolution when $\lambda=2.0$

which differential equations of motion can be written. Fig. 4 shows the physical model chosen. The turbine rotor is represented by two rotational inertias, the positions of which are specified by $\theta_{1}$ and $\theta_{2}$, each with one-half of the total

TORQUE RIPPLE MODEL

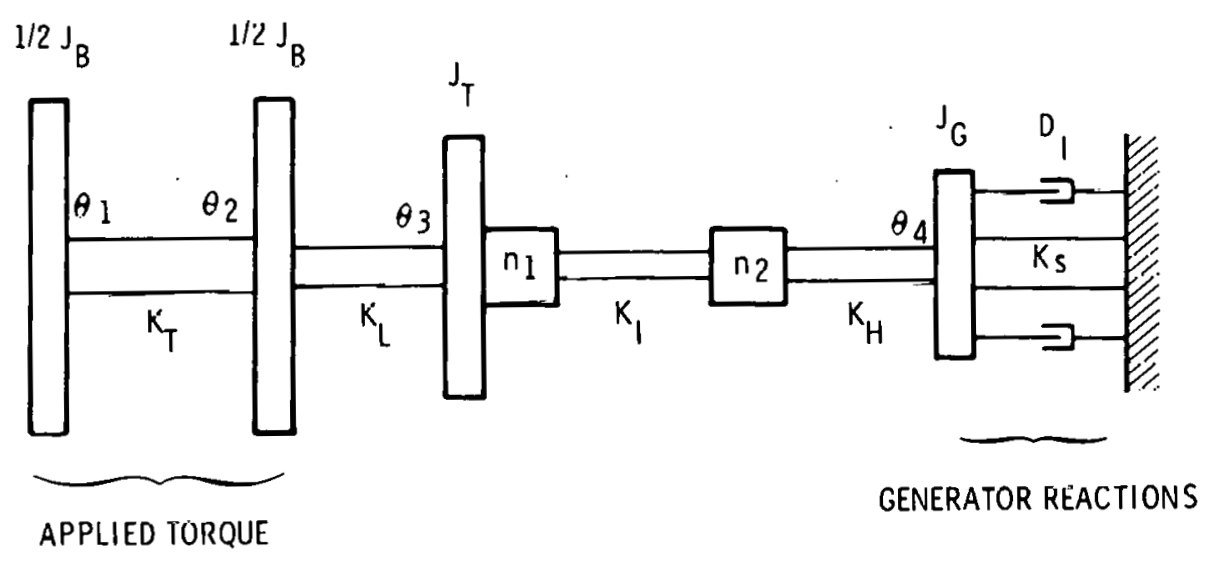

Figure 4. Sohcmatic of turbine drive train components and nomenclature. 
rotor inertia, and which are connected together by a torsional shaft representing the rotor tower, with a stiffness, $\mathrm{K}_{\mathrm{T}}$, chosen to yield the correct counter-rotating frequency for the rotor. Continuing downstream, the equivalent low speed shaft (stiffness $=\mathrm{K}_{\mathrm{L}}$ ) transmits torque to the transmission with its inertia, $\mathrm{J}_{\mathrm{T}}$, fixed gear ratio, $\mathrm{n}_{1}$, and position, $\theta_{3}$. The interchangeable pulleys and timing belt have an incrementally adjustable, but operationally fixed gear ratio, $n_{2}$, and are connected upstream to the transmission with an equivalent intermediate speed shaft (stiffness $=k_{I}$ ) and downstream to an electric generator with an equivalent high speed shaft (stiffness $=\mathrm{K}_{\mathrm{H}}$ ). The electric generator (inertia $=\mathrm{J}_{\mathrm{G}}$ and position $=\theta_{4}$ ) may be either synchronous or induction, with torque reactions proportional to rotational position or speed, respectively. The proportionality constant is $\mathrm{K}_{S}$ for a synchronous generator, and $D_{I}$ for an induction generator. Although results in this work are limited to those for an induction generator only, $\mathrm{k}_{S}$ is retained in the solution for generality. This physical representation of the drive train captures torsional vibration modes of interest.

The second element of the torque ripple model embodies a decomposition ${ }^{6}$ of the functional dependence upon time of the applied aerodynamic torque as predicted by the vortex model ${ }^{3}$ for low tip speed ratios and the stream tube models ${ }^{4}$ for high tip speed ratios. (Changing from the vortex to the stream tube models is done to conserve computer time and reduce computation cost). The applied torque can be distributed fractionally between the two rotor inertias in order to account for vertical wind shear, if necessary, and has the form

$$
\begin{aligned}
& T_{1 A}=T_{10}+\sum_{i=1}^{N} T_{1 i} \cos \omega_{i} t+\sum_{i=1}^{N} \bar{T}_{1 i} \sin \dot{\omega}_{i} t \\
& T_{2 A}=T_{20}+\sum_{i=1}^{N} T_{2 i} \cos \omega_{i} t+\sum_{i=1}^{N} \bar{T}_{2 i} \sin \omega_{i} t
\end{aligned}
$$


$\mathrm{T}_{1 \mathrm{~A}}$ and $\mathrm{T}_{2 \mathrm{~A}}$ are applied to the top (upstream) half and bottom (downstream) half of the rotor, respectively.

The third model element consists of a solution to the equations of motion, taken in the form

$$
\theta_{j}=A_{j 0}+\sum_{i=1}^{N} A_{j i} \cos \omega_{i} t+\sum_{i=1}^{N} \bar{A}_{j i} \sin \omega_{i} t+\Omega_{j} t
$$

where, repeating, $\theta_{1}$ and $\theta_{2}$ are the angular positions of the top and bottom rotor halves, respectively, $\theta_{3}$ is the angular position of the low speed end of the transmission and $\theta_{4}$ is the angular position of the generator. $\Omega_{1}\left(=\Omega_{2}\right)$ is the mean operating speed of the turbine, $\Omega_{3}$ is the mean speed of the slow speed end of the transmission, and $\Omega_{4}$ is the mean operating speed of the generator (note that $\Omega_{3}=\Omega_{4} / n_{1} n_{2}$ ). since torsional modes of the turbine system which are reacted by torque in the drive train are even multiples of the operating speed ${ }^{7}, \omega_{i}=2 i \Omega_{I}$.

Equations of motion for the physical representation of the torque ripple model depicted by Fig. 4 are

$$
\begin{aligned}
& \frac{1}{2} J_{B} \ddot{\theta}_{1}+K_{T}\left(\theta_{1}-\theta_{2}\right)=T_{1 A} \\
& \frac{1}{2} J_{B} \ddot{\theta}_{2}+K_{L}\left(\theta_{2}-\theta_{3}\right)+K_{T}\left(\theta_{2}-\theta_{1}\right)=T_{2 A} \\
& J_{T} \ddot{\theta}_{3}+K_{3}\left(\theta_{3}-\frac{\theta_{4}}{n_{1} n_{2}}\right)+K_{L}\left(\theta_{3}-\theta_{2}\right)=0 \\
& J_{G} \ddot{\theta}_{4}+K_{4}\left(\theta_{4}-n_{1} n_{2} \theta_{3}\right)+K_{S}\left(\theta_{4}-\omega_{S} t\right)+D_{I}\left(\dot{\theta}_{4}-\omega_{S}\right)=0
\end{aligned}
$$


After a substitution of (1) and (2) into (3), and a substantial amount of algebra, the following results are obtained for determination of the unknown constants.

$$
\begin{aligned}
& A_{1 i}=\frac{\lambda_{2 i} \lambda_{3 i}-\lambda_{1 i} \lambda_{4 i}}{\left(\lambda_{1 i}{ }^{2}+\lambda_{2 i}{ }^{2}\right)}, \bar{A}_{1 i}=\frac{\lambda_{1 i} \lambda_{3 i}+\lambda_{2 i} \lambda_{4 i}}{\left(\lambda_{1 i}{ }^{2}+\lambda_{2 i}{ }^{2}\right)} \\
& A_{21}=\frac{\phi_{1 i} A_{11}-T_{11}}{K_{T}} \quad, \bar{A}_{2 i}=\frac{\phi_{1 i} \bar{A}_{1 i}-\bar{T}_{1 i}}{K_{T}} \\
& A_{3 i}=\frac{1}{K_{T} K_{L}}\left[\left(\phi_{1 i} \phi_{2 i}-K_{T}^{2}\right) A_{1 i}-\left(K_{T} T_{2 i}+\phi_{2 i} T_{1 i}\right)\right] \\
& \bar{A}_{3 i}=\frac{1}{K_{T} K_{L}}\left[\left(\phi_{1 i} \phi_{2 i}-K_{T}{ }^{2}\right) \bar{A}_{1 i}-\left(K_{T} \bar{T}_{2 i}+\phi_{2 i} \bar{T}_{1 i}\right)\right] \\
& A_{4 i}=\frac{n_{1} n_{2}}{K_{T} K_{L} K_{3}}\left\{\left[\phi_{31}\left(\phi_{1 . i} \phi_{2 i}-K_{T}{ }^{2}\right)-\phi_{11} K_{L}{ }^{2}\right] A_{11}\right. \\
& \left.+\left[K_{L}{ }^{2} T_{1 i}-\phi_{3 i}\left(K_{T} T_{2 i}+\phi_{2 i} T_{1 i}\right)\right]\right\} \\
& \bar{A}_{4 i}=\frac{n_{1} n_{2}}{K_{T} K_{L} K_{3}} \int\left[\phi_{3 i}\left(\phi_{1 i} \phi_{2 i}-K_{T}^{2}\right)-\phi_{1 i} K_{L}^{2}\right] \bar{A}_{1 i} \\
& \left.+\left[\mathrm{K}_{\mathrm{L}}{ }^{2} \overline{\mathrm{T}}_{1 i}-\phi_{3 i}\left(\mathrm{~K}_{\mathrm{T}} \overline{\mathrm{T}}_{2 i}+\phi_{2 i} \overline{\mathrm{T}}_{1 i}\right)\right]\right\}
\end{aligned}
$$

where

$$
\begin{aligned}
& \phi_{1 i}=\left(\mathrm{K}_{\mathrm{T}}-\omega_{i}^{2} \mathrm{~J}_{B} / 2\right) ; \phi_{21}=\left(\mathrm{K}_{\mathrm{T}}+\mathrm{K}_{\mathrm{L}}-\omega_{i}{ }^{2} \mathrm{~J}_{\mathrm{B}} / 2\right) \\
& \phi_{3 i}=\left(k_{L}+k_{3}-\omega_{i}^{2} J_{T}\right), \phi_{4 i}=\left(k_{4}+k_{S}-\omega_{i}^{2} J_{G}\right) \\
& \lambda_{11}=\omega_{i} D_{I}\left[\phi_{3 i}\left(\phi_{1 i} \phi_{2 i}-K_{T}^{2}\right)-\phi_{1 i} K_{L}^{2}\right] \\
& \lambda_{2 i}=\left(\phi_{3 i} \phi_{4 i}-K_{3} K_{4}\right)\left(\phi_{1 i} \phi_{2 i}-K_{T}{ }^{2}\right)-\phi_{1 i} \phi_{4 i} K_{L}{ }^{2}
\end{aligned}
$$

14 


$$
\begin{aligned}
& \lambda_{31}=\left(\phi_{3 i^{\phi}}{ }-K_{3} K_{4}\right)\left(K_{T^{I} 2 i}+\phi_{2 i}{ }^{T} 1 i\right)-\phi_{4 i} K{ }^{2} T_{1 i} \\
& -\omega_{i} D_{I}\left[{ }_{Z}{ }^{2} \bar{T}_{1 i}-\phi_{3 i}\left(K_{T} \bar{T}_{2 i}+\phi_{2 i} \cdot \bar{T}_{1 i}\right)\right] \\
& \lambda_{41}=\left(\phi_{31} \phi_{41}-K_{3} K_{4}\right)\left(K_{T} \bar{T}_{2 i}+\phi_{2 i} \bar{T}_{1 i}\right)-\phi_{4 i} K_{L} \bar{T}_{11} \\
& +\omega_{1} \mathrm{D}_{I}\left[\mathrm{~K}_{\mathrm{L}}{ }^{2} \mathrm{~T}_{1 i}-\phi_{3 i}\left(\mathrm{~K}_{\mathrm{T}} \mathrm{T}_{2 i}+\phi_{2 i} \mathrm{~T}_{1 i}\right)\right] \\
& \mathrm{K}_{3}=\frac{\mathrm{n}_{1}{ }^{2} \mathrm{n}_{2}{ }^{2} \mathrm{~K}_{\mathrm{I}} \mathrm{K}_{\mathrm{H}}}{\mathrm{K}_{\mathrm{I}}+\mathrm{n}_{2}{ }^{2} \mathrm{~K}_{\mathrm{H}}} \\
& \mathrm{K}_{4}=\mathrm{K}_{3} / \mathrm{n}_{1}{ }^{2} \mathrm{n}_{2}{ }^{2}
\end{aligned}
$$

which completes the solution derivation.

NUMERICAL RESULTS AND ALLOWABLE LEVELS

Numerical results presented here are based on drive train properties of the present DOE/Sandia 17-meter research turbine. They are:

$$
\begin{aligned}
& \mathrm{J}_{\mathrm{B}}=2.92 \times 10^{5} \mathrm{lb}-\mathrm{sec}^{2}-\mathrm{in}\left(3.30 \times 10^{4} \mathrm{~N}-\mathrm{sec}^{2}-\mathrm{m}\right) \\
& \mathrm{J}_{\mathrm{T}}=2.15 \times 10^{3} \mathrm{lb}-\mathrm{sec}^{2}-\mathrm{in}\left(2.43 \times 10^{2} \mathrm{~N}-\mathrm{sec}^{2}-\mathrm{m}\right) \\
& \mathrm{J}_{\mathrm{M}}=27.1 \mathrm{lb}-\mathrm{sec}^{2}-\mathrm{in}\left(3.06 \mathrm{~N}-\mathrm{sec}^{2}-\mathrm{m}\right) \\
& \mathrm{D}_{\mathrm{I}}=824.01 \mathrm{~b}-\mathrm{in}-\mathrm{sec} / \mathrm{rad}(93.1 \mathrm{~N}-\mathrm{m}-\mathrm{sec} / \mathrm{rad}) \\
& \mathrm{K}_{\mathrm{T}}=1.46 \times 10^{8} \mathrm{lb}-\mathrm{in} / \mathrm{rad}\left(1.65 \times 10^{6} \mathrm{~N}-\mathrm{m} / \mathrm{rad}\right) \\
& \mathrm{K}_{\mathrm{L}}=2.39 \times 10^{6} \mathrm{lb}-\mathrm{in} / \mathrm{rad}\left(2.69 \times 10^{5} \mathrm{~N}-\mathrm{m} / \mathrm{rad}\right) \\
& \mathrm{K}_{\mathrm{I}}=1.25 \times 10^{6} \mathrm{lb}-\mathrm{in} / \mathrm{rad}\left(1.41 \times 10^{5} \mathrm{~N}-\mathrm{m} / \mathrm{rad}\right) \\
& \mathrm{K}_{\mathrm{H}}=1.86 \times 10^{4} 1 \mathrm{~b}-\mathrm{in} / \mathrm{rad}\left(2.10 \times 10^{3} \mathrm{~N}-\mathrm{m} / \mathrm{rad}\right) \\
& \mathrm{n}_{1}=35.6 \\
& \mathrm{n}_{2}=\frac{1800}{\mathrm{n}_{1}(\Omega)} \\
& \mathrm{T}_{\mathrm{R}}=8.35 \times 10^{3} \mathrm{ft}-1 \mathrm{~b}\left(1.13 \times 10^{2} \mathrm{~N}-\mathrm{m}\right)
\end{aligned}
$$


where 1800 is the rotational speed of the generator and $\Omega$ is the rotational speed of the turbine, both in units of RPM, and $\mathrm{T}_{\mathrm{R}}$ is the torque rating of the turbine. Before defining torque ripple explicitly, it is necessary to derive an expression for torque as a function of time for some specified drive train location. After preliminary numerical evaluation, it was observed that, for the above set of properties, torque ripple in the drive train is essentially independent of location. Therefore, it is only necessary to know the torque in the low speed end, $T_{L}(t)$. It is given by $T_{L}(t)=K_{L}\left(\theta_{3}-\theta_{2}\right)$, and with the above solution

$$
\begin{aligned}
T_{L}(t) & =K_{2}\left[\sum_{i=1}^{N}\left(A_{3 i} \cos \omega_{i} t+\bar{A}_{3 i} \sin \omega_{i} t\right)\right. \\
& \left.-\sum_{i=1}^{N}\left(A_{2 i} \cos \omega_{i} t+\bar{A}_{2 i} \sin \omega_{i} t\right)-\frac{T_{10}+T_{20}}{K_{L}}\right]
\end{aligned}
$$

Torque ripple is defined in two ways. 'l'he flrst, labeled $\tilde{\mathrm{T}}_{\mathrm{M}}$ ' is the ratio of the mean-to-peak value and the mean value of torque, and is a convenient form when considering fatigue characteristics of the drive train components. The gecond, labled $\tilde{T}_{R}$ ' is the ratio of the mean-to-peak value and the turbine's rated torque, and is relatable to power quality. Thus, from (4)

$$
\begin{aligned}
& \tilde{T}_{M}=\frac{T_{\text {LMAX }}-T_{\text {LMIN }}}{T_{\text {LMAX }}+T_{\text {LMIN }}} \\
& \tilde{T}_{R}=\frac{T_{\text {LMAX }}-T_{\text {LMIN }}}{2 T_{\text {LRATED }}}
\end{aligned}
$$


In order to facilitate numerical evaluation of torque ripple a computer code; named FATE, was written. Applied torque coefficients, found in (1), are used as input to the code and results for $\tilde{\mathrm{T}}_{M}$ and $\tilde{\mathrm{T}}_{\mathrm{R}}$ are calculated for discrete values of $\lambda$. (The coefficients of (1) vary with $\lambda$ ). Fig. 5 shows how torque ripple, using both definitions, varies with tip speed ratio for the DOE/Sandia research turbine operating at $50.6 \mathrm{rpm}$.

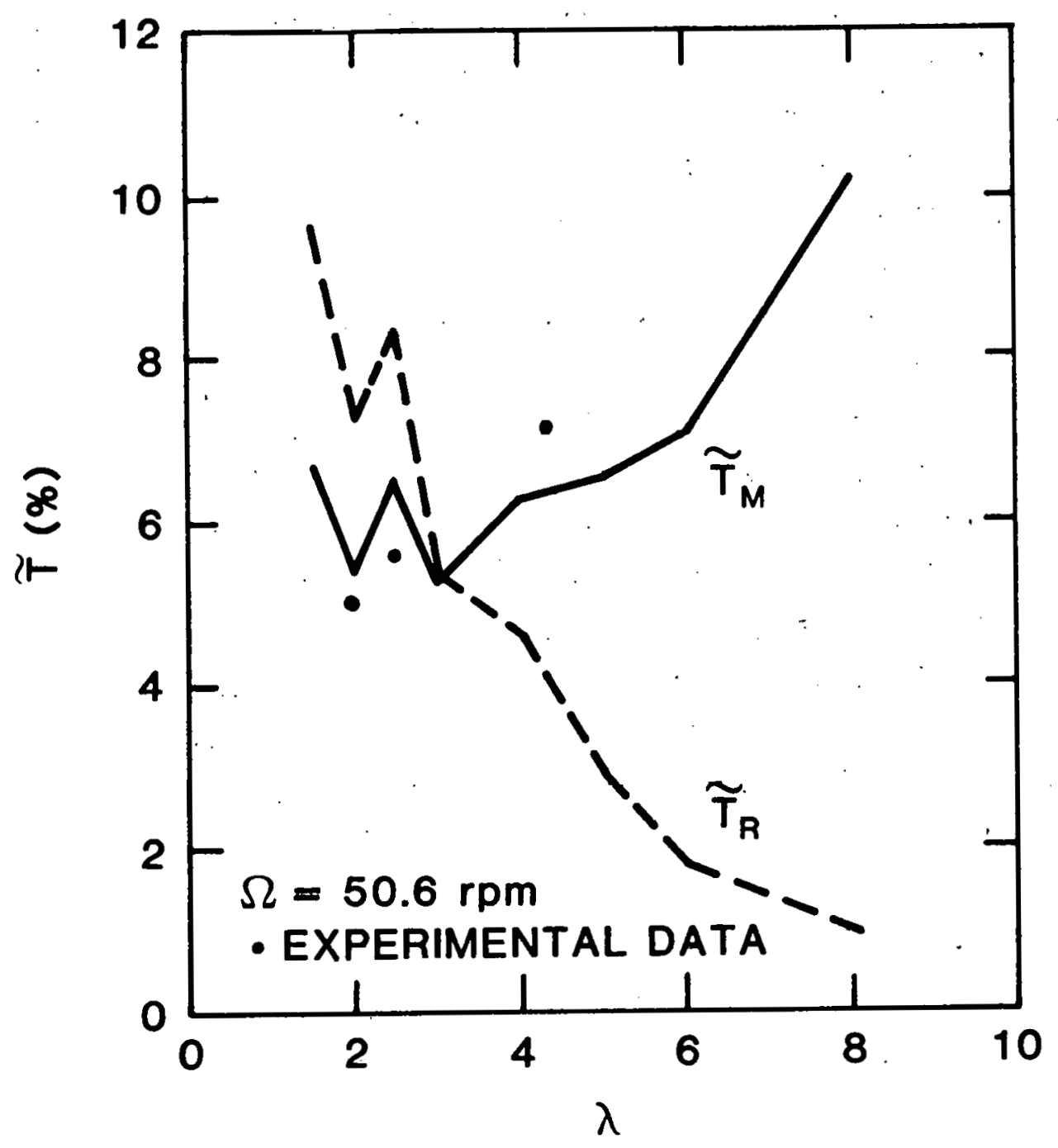

Figure 5. Torque ripple versus tip speed ratio for the DOE/Sandia research turbine operating at 50.6 RHM. 
Because of the rapid changes in $\tilde{T}$ at low values of $\lambda$, calculated points are connected by straight lines. Three data points, based on the $\tilde{\mathrm{T}}_{\mathrm{M}}$ definition, are shown in the figure and agree closely with predicted values of $\tilde{T}_{M}$. These data are obtained by a torque sensor located in the low speed end of the drive train. More data are not presented because of the difficulty in obtaining experimental information not influenced by the random nature of the wind. Notice that $\tilde{T}_{M}$ increases with $\lambda$. This occurs because even though the oscillating portion of the torque is diminishing with $\lambda$, the mean value is diminishing faster, thus causing $\tilde{\mathrm{T}}_{M}$ to increase. $\dot{\mathrm{T}}_{R}$ shows the change in only the oscillating portion of torque (since it is normalized by a constant--the turbine rated torque), where it is seen to decrease with increasing $\lambda$.

To determine what level of torque ripple might be allowable from a fatigue or life expectancy standpoint, assume that drive train components follow the Goodman law for fatigue strength ${ }^{8}$. This law imposes a straight line relationship between fatigue strength for purely alternating stress (the dependent variable) and mean stress (the independent variable). Using this law and the above definftion of torque ripple expressed as a of of mean torque, $\tilde{T}_{M}$, an expression for allowable $\tilde{\mathrm{T}}_{M}$ in terms of expected fatigue strength, $\sigma_{N}$, mean stress, $\sigma_{M}$, and ultimate strength, $\sigma_{U}$, of drive train components was derived. $I t$ is

$$
\dot{\mathrm{T}}_{M} \leq\left(\frac{\sigma_{\mathrm{N}}}{\sigma_{\mathrm{U}}}\right)\left(\frac{\sigma_{U}}{\sigma_{M}}-1\right)
$$

Taking the fatigue limit for $\sigma_{N}$, a typical value of the ratio, $\left(\sigma_{\mathrm{N}} / \sigma_{U}\right)$; for structural steels is 0.4 . Unsing this value, 
(7) can be plotted versus the ratio $\left(\sigma_{U} / \sigma_{M}\right)$ as in Fig. 6 . Since $\left(\sigma_{U} / \sigma_{M}\right)$ may be viewed as a safety factor for design of drive train components, whatever value is used can be located on the ordinate of Fig. 6 , and as long as the $\tilde{\mathrm{T}}_{M}$ calculated from (5), falls on or below the line in Fig. 6 , infinite life can be expected. By taking the ratio, $\tilde{\mathrm{T}}_{R} / \tilde{\mathrm{T}}_{M^{\prime}}$,

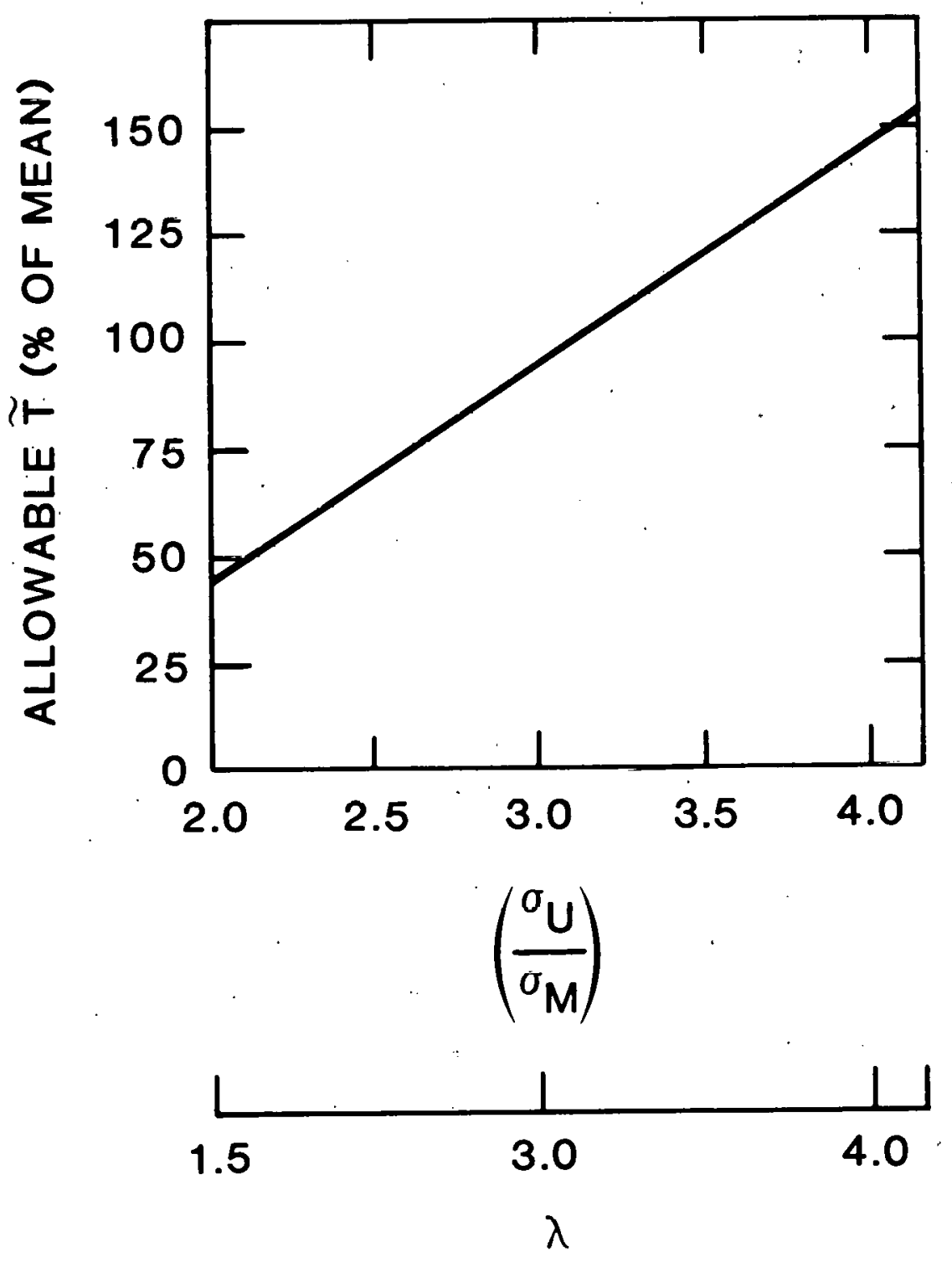

Figure 6. Allowable values of torque ripple (expressed as a $z$ of mean torque) based on infinite life of drive 'tra'in components. 
for specific values of $\lambda$ (for example from Fig. 5), it can be seen that as $\lambda$ increases, $\sigma_{M}$ decreases. Thus, increasing $\lambda$ corresponds to an increase in $\left(\sigma_{U} / \sigma_{M}\right)$ and, therefore, an increase in acceptable levels of $\tilde{\mathrm{T}}_{\mathrm{M}}$. For the DOE/Sandia research turbine, a design safety factor of 2.0 was used for drive train components. Since maximum torque occurs at $\lambda \simeq 1.5,\left(\sigma_{U} / \sigma_{M}\right)=2.0$ on the abscissa in Fig. 6 corresponds to $\lambda=1.5$. Using $F$ ig. 5 , it can be seen that $\left(\sigma_{U} / \sigma_{M}\right) \simeq 3.0$ corresponds to $\lambda=3.0,\left(\sigma_{U} / \sigma_{M}\right) \simeq 4$ corresponds to $\lambda=4.0$, and $\left(\sigma_{U} / \sigma_{M}\right) \simeq 6.5$ corresponds to $\lambda=6$. This demonstrates that the allowable values of 'i'M increase rapidly with $\lambda$. Examination of the values of $\tilde{\mathrm{T}}_{\mathrm{M}}$ in Fig. 5 indicates that the DOE/Sandia research turbine does not have a fatigue problem.

Power companies have determined that power quality determination is dominated by the amount of "light flicker" that people will tolerate for extended periods of time ${ }^{9}$. They have also determined that the "borderline of irritation" with 60 cycle power corresponds to a voltage variation of $0.5 \%$ of the line voltage. (This percent var-iation-may be higher if energy is used only to power electrical equipment.) since torque ripple in a generator is equivalent to current ripple in the line, acceptable torque ripple (expressed as a $z$ of rated torque) can be related to voltage ripple. In the case of the DOE/Sandia research turbine, line impedance is approximately $4 \%$ of the load impedance. A maximum voltage ripple of $0.5 \%$, therefore, corresponds to an allowable $\tilde{\mathrm{T}}_{\mathrm{R}}$ of 12.58. Results in Fig. 5 indicate that the research turbine does not have a power quality problem.

CONTROL OF TORQUE RIPPLE

Among the properties which characterize the torque ripple. problem, the most readily and easily modified are drive train 
torsional rigidities and perhaps, generator slip. Fig. 7 shows numerical results for $\tilde{\mathrm{T}}_{\mathrm{M}}$ versus $\lambda$ for the research turbine

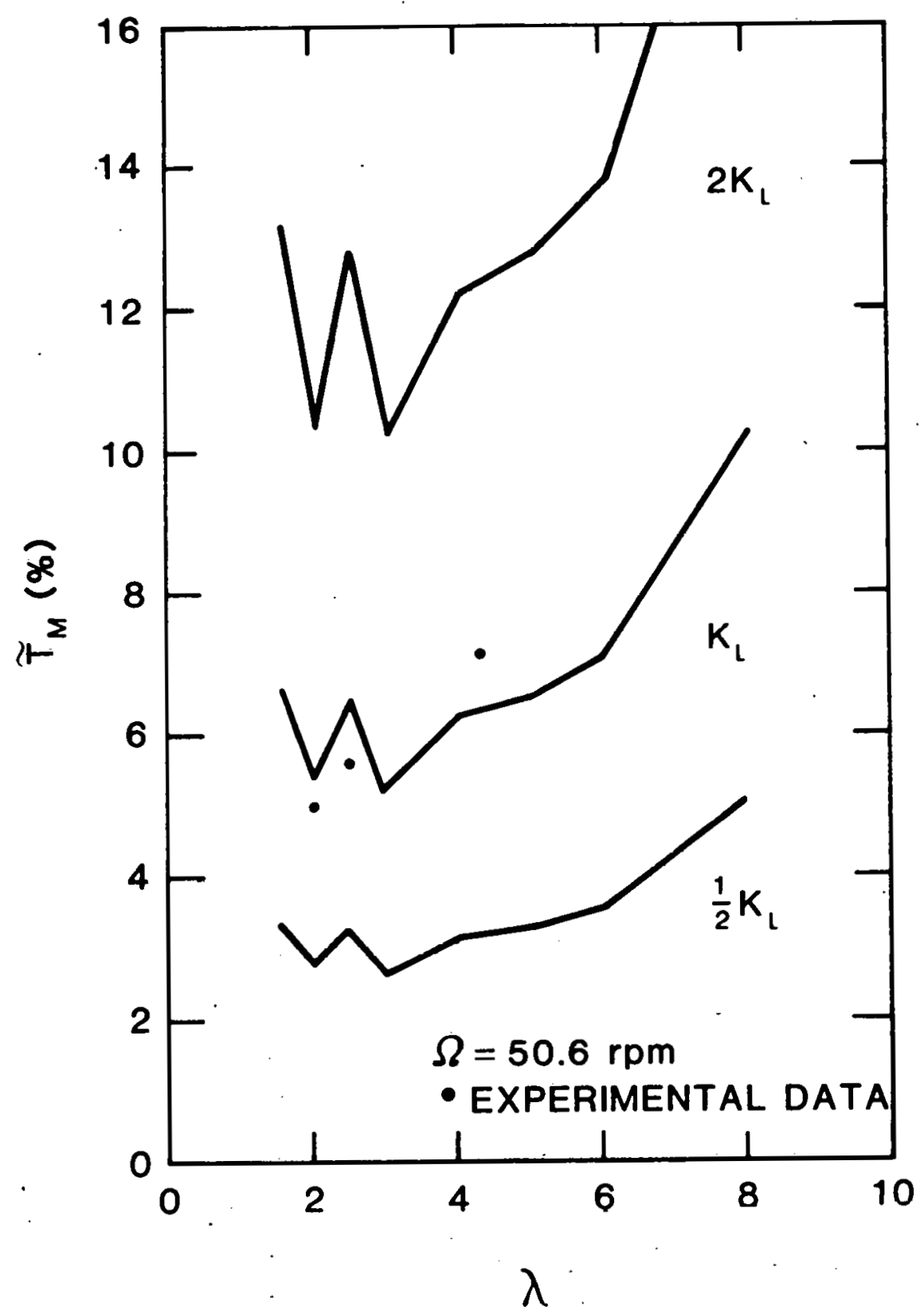

Figure 7. Torque ripple (expressed as a $z$ of mean torque) versus tip speed ratio for various values of low speed drive train stiffness. 
and values which would have resulted from a doubling and a halving of the torsional rigidity of the low speed end of its drive train. While fatigue life does not appear to be reduced even with a doubling of the low speed stiffness, additional rigidity increases could cause problems. Since $\tilde{T}_{R} \simeq \tilde{T}_{M}$ when $\lambda \simeq 1.5$, doubling the stiffness of the low speed end could cause a noticeable reduction in power quality.

To see how a change in low speed torsional stiffness effects torque ripple, consider the results in Fig. 8 , where $\tilde{T}_{M}$ is plotted, for three low speed rigidities, as a function of turbine operating speed, $\Omega$. Notice how the peak (which corresponds to the first critical drive train frequency) moves to the left with a reduction in low speed stiffness and to the right for an increase in drive train stiffness. The effect that this has on torque ripple at a specified operating speed is obvious. (This figure does not depict what occurs during start up. It provides torque ripple values in the drive train at specified operating speeds.) The behavior of $\tilde{\mathrm{T}}_{\mathrm{R}}$ with $\Omega$ is similar to that shown for $\widetilde{\mathrm{T}}_{\mathrm{M}}$ in Fig. 8. Other methods of controlling torque ripple exist. An increase in generator slip tends to lower torque ripple values at moderate $\Omega$, and increase them at higher $\Omega$ (above $\sim 40$ RPM). An increase in inertia properties tends to lower torque ripple at a given operating condition, but this may be costly. A reduction in gear ratio tends to lower apparent drive train rigidities and, thus, lower torque ripple. However, the most effective means of reducing torque ripple is through reduction of low speed rigidity. This can be shown as follows.

Let $k_{1}$ represent either the low speed (between the rotor and the transmission) drive train stiffness or the high speed (between the transmission and the generator) stiffness, and let $\mathrm{K}_{2}$ represent the other. Assume that the high speed stiffness has been corrected to the low speed end by multiplying it by 


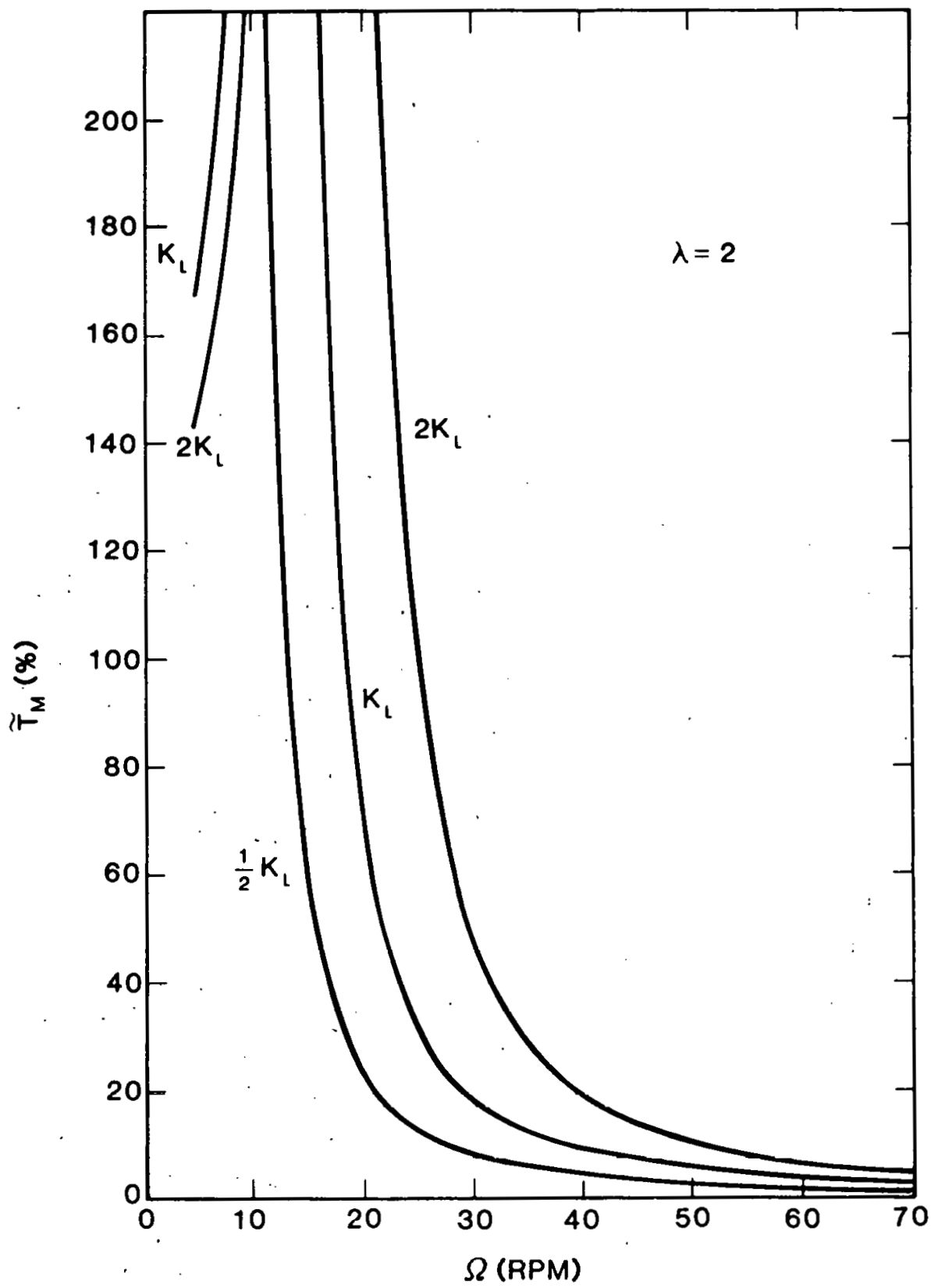

Figure 8. Torque ripple (expressed as a 8 of mean torque) versus turbine nperating spepd for various values of low speed drive train stiffness. 
the square of the drive train speed ratio. Let the entire drive train stiffness by represented by $\bar{k}$. Then

$$
\overline{\mathrm{K}}=\frac{\mathrm{K}_{1} \mathrm{~K}_{2}}{\mathrm{~K}_{1}+\mathrm{K}_{2}}
$$

The change in $\bar{K}$ can be expressed in terms of. $k_{1}$ and $k_{2}$ and a change in either of these, say $\Delta \mathrm{K}_{1}$.

$$
\frac{\Delta \bar{K}}{\mathrm{~K}}=\frac{\Delta \mathrm{K}_{1}}{\mathrm{~K}_{1}} \quad\left(\frac{\mathrm{K}_{2}}{\mathrm{~K}_{1}+\mathrm{K}_{2}+\Delta \mathrm{K}_{1}}\right)
$$

Now, let $\mathrm{K}_{1}$ represent the high speed stiffness and recognize that $\mathrm{K}_{1}>\mathrm{K}_{2}$. From (9)

$$
\lim \frac{\Delta \overline{\mathrm{R}}_{2}}{\mathrm{~K}} \rightarrow 0 \text { as } \frac{\mathrm{K}_{2}}{\mathrm{~K}_{1}} \rightarrow 0
$$

which implies that, for a given change in the high speed stiffness, the net effect is nearly zero. Now let $\mathrm{K}_{2}$ represent the high speed stiffness and recognize that $k_{2}>k_{1}$. From (9)

$$
\lim \frac{\Delta \bar{K}}{K} \rightarrow \frac{\Delta \mathrm{K}_{1}}{\mathrm{~K}_{1}} \text { as } \frac{\mathrm{K}_{1}}{\mathrm{~K}_{2}} \rightarrow 0
$$

This implies that a change in the new speed stiffness will result in approximately an equivalent change in the overall 
drive train stiffness. Therefore, drive train stiffness changes are most effective when made at the low speed end. This result depends upon the high speed stiffness being much greater than the low speed stiffness, a condition which is nearly always true because of the effect that the speed ratio has on the high speed stiffness.

\section{CONCLUSIONS AND RECOMMENDATIONS}

Currently, the deterministic torque $r$ ipple problem is well understood. The source of torque ripple, its behavior with operating conditions, its response to property changes, and its allowable levels have been analytically predicted and experimentally verified. (Also, see Reference 1). Torque ripple in two-bladed VAWT systems can be maintained at acceptable levels.

As mentioned earlier, collection of data for correlation with the deterministic solution is difficult. This is due to the stochastic nature of the wind which tends to increase measured torque ripple in the turbine drive train above values predicted by the deterministic model. As turbines increase in size, their natural frequencies are reduced and their response times more nearly match the frequency content of the wind, thus aggravating the problem. Logically, the next step in torque ripple modeling should deal with the stochastic nature of the wind, in terms of both its magnitude and its direction. It is this author's feeling, however, that this additional characterization will have to begin with a modification of the aerodynamic codes which predict the torque applied to the turbine. 
ACKNOWLEDGMENT

The willing and frequent assistance of G. M. McNerney, New Mexico Engineering Research Institute, University of New Mexico, in providing the Fourier coefficients of the applied torque used in the numerical evaluation of torque ripple is gratefully acknowledged.

\section{REFERENCES}

1. Reuter, R. C. and Worstell, M. H., "Torque Ripple in a Vertical Axis Wind Turbine," Sandia National Laboratories Report No. SAND78-0577, April 1978.

2. Mirandy, L. P., "Rotor/Generator Isolation for Wind Turbines," Journal of Energy, Vol. 1, No. 3, May-June, 1977.

3. Strickland, J. H., Webster, B. T., and Nguyen, T., "A Vortex Model of the Darrieus Turbine: An Analytical and Experimental Study," Sandia National Laboratories Report No. SAND79-7058, Feb. 1980.

4. Klimas, P. C., and Sheldahl, R. E., "Four Aerodynamic Prediction Schemes for Vertical Axis Wind Turbines: A Compendium," Sandia National Laboratories Report No. SAND78-0014, June 1978.

5. Worstell, M. H., "Aerodynamic Performance of the 17-Meter-Diameter Darrieus Wind Turbine," Sandia National Laboratories Report No. SAND78-1737, Jan. 1979.

6. McNerney, G. M., "Fourier Coefficients of Aerodynamic Torque Functions for the DOE/Sandia 17-M Vertical Axis Wind Turbine," Sandia National Laboratories Report No. SAND79-1508, Feb. 1980.

7. Lobitz, D. W. and Sullivan, W. N., "VAWTDYN--A Numerical Package for the Dynamic Analysis of Vertical Axis Wind Turbines," ASME Paper Presented at Nov. 1980 WAM.

8. Richards, C. W., Engineering Materials Science, Wadsworth Publishing Company, Inc., San Francisco, 1961.

9. Barton, R. S., Bowler, C. E. J. and Piwko, R. J., "Control and Stabilization of the DOE/NASA MOD-l Two Megawatt Wind Turbine Generator," Proceedings, 14th Intcrsociety Energy Conversion Engineering Conference, Boston, MA, Aug, 1979. 
DISTRIBUTION :

TID-4500-R66 UC-60 (283)

Aero Engineering Department (2)

Wichita state University

Wichita, KS 67208

Attn: M. Snyder

W. Wentz

R. E. Akins, Assistant Professor Department of Engineering Science and Mechanics

Virginia Polytechnic Institute and state university

Blacksburg, VA 24060

Alcoa Laboratories (5)

Alcoa Technical Center

Aluminum Company of America

Alcoa Center, PA 15069

Attn: D. K. A $i$

A. G. Craig

J. T. Huang

J. R. Jombock.

P. N. Vosburgh

Mr. Robert B. Allen

General Manager

Dynergy Corporation

P.O. Box 428

1269 Union Avenue

Laconia, $\mathrm{NH} 03246$

American Wind Energy Association

1609 Connecticut Avenue NW

Washington, DC 20009

E. E. Anderson

South Dakota School of Mines and Technology

Department of Mechanical Engineering

Rapid City, SD 57701

Scott Anderson

318 Millis Hall

University of Vermont

Burlington, VT 05405

G. T. Ankrum

DOE/Office of Commercialization

20 Massachusetts Avenue NW

$\mathrm{N}_{1}$ ili Station $2221 \mathrm{C}$

washington, DC 20585
Holt Ashley

Stanforả University

Department of Aeronautics and

Astronautics Mechanical Eng

Stanford, CA 94305

Kevin Austin

Consolidated Edison Company of New York, Inc.

4 Irving Place

New York, NY 10003

F. K. Beohtel

Washington State University

Department of Electrical Eng

College of Engineering

pullman, WA 99163

M. E. Beecher

Arizona state University

Solar Energy Collection

University Library

Tempe, AZ 85281

K. Bergey

University of Oklahoma

Aero Engineer iny Department

Norman, OK 73069

Steve Blake

Wind Energy systems

Route 1, Box 93-A

Oskaloosa, KS 66066

Robert Brulle

McDonnel1-Douglas Aircraft Corp P.O. Box 516

Department 341 , Building $32 / 2$

St. Louis, MO 63166

R. Camerero

Faculty of Applied Science

University of Sherbrooke

Sherbrooke, Quebec

CANADA JIK 2Rl

CERCEM

49 Rue du Commandant Rolland

93350 Le Bourget

FRANCE

Attn: G. Darrieus

$\therefore$ Delassus 
Professor V. A. L. Chasteau

School of Engineering

University of Auckland

Private Bag

Auckland, NEW ZEALAND

Howard T. Clark

McDonnell Aircraft Corporation P.O. Box 516

Department 337 , Building 32

st. Louis, MO 63166

Dr. R. N. Clark

USDA, Agricultural Research Serv Southwest Great Plains Research Bushland, TX 79012

Joan D. Cohen

Consumer Outréach Coordinator

State of New York

Executive Department

State Consumer protection Board

99 Washington Avenue

Albany, NY 12210

Dr. D. E. Cromack

Associate Professor

Mechanical and Aerospace Eng

Department

University of Massachusetts

Amherst, MA 01003

Gale B. Curtis

Tumac Industries

650 Ford street

Colorado Springs, co 80915

DOE/ALO (3)

Albuquerque, NM 87185

Attn: G. P. Tennyson

D. C. Graves

D. W. King

DOE Headquarters (20)

Washington, DC. 20545

Attn: L. V. Livone, Chief

wind Systems Branch

D. F. Ancona, Program Mgr

wind Systems Branch

C. $\dot{\text { W. Dodd }}$

School of Engineering

Southern Illinois University

Carbondale, IL 62901
Dominion A:uminum Fasricating Ltd.

3570 Hawkestone Road

Mississauga, Ontario

CANADA L5C 208

Attn: L. Schienbein

C. Wood

D. P. Dougan

Hamilton Standard

1730 NASA Boulevard

Room 207

Houston, TX 77058

J. B. Dragt

Nederlands Energy Research Found

Physics Department

westerduinweg 3 patten ( $\mathrm{nh}$ )

THE NETHERLANDS

C. E. Elderkin

Battelle-Pacific Northwest Lab

P.O. Box 999

Richland, WA 99352

Frank R. Eldridge, Jr.

The Mitre Corporation

1820 Dolley Madjson Blva.

McLean, VA 22102

Electric Power Research Inst

3412 Hillview Avenue

Palo Alto, CA 94304

Attn: E. Demeo

James D. Fock, Jr.

Department of Aerospace Eng

University of Colorado

Boulder, $\mathrm{CO} \cdot 80309$

Dr. Lawrence C. Frederick

Public Service Company of New Hamp

$1000 \mathrm{Elm}$ street

Manchester, NH 03105

E. Gilmore

Amarillo College

Amarillo, .TX 79100

Paul Gipe

wind Power Digest

P.O. 30x 539

Harrigblira P! 17108 
Roger T. Griffiths

University College of Swansea

Department of Mechanical Eng

Singleton Park

Swansea SA2 8PP

UNITED KINGDOM

Professor N. D. Ham

Massachusetts Institute of Tech

77 Massachusetts Avenue

Cambridge, MA 02139

Sam Hansen

DOE/DST

20 Massachusetts Avenue

Washington, DC 20545

C. F. Harris

Wind Eng ineering Corporation

Airport Industrial Area

Box 5936

Lubbock, TX 79415

W. L. Harris

Aero/Astro Department

Massachusetts Institute of Tech

Cambridge, MA 02139

Terry Healy (2)

Rockweli International

Rocky ilats Plant

P.O. Box 464

Golden, co 80401

Helion

P.O. Box 4301

Sylmar, CA 91342

Don Hinrichsen

Associate Editor

AMBIO

KVA

Fack, S-10405

stockholm

SWEDEN

Sven Hugosson

Box 21048

S. 10031 stockholm 21

SWEDEN

O. Igra

Department of Mechanical Eng

Ben-Gurion University of the Negev

Beer-Sheva, ISRAEL
Ind a: o:..crporation, Ltd.

Marketing Division

254-C, Dr. Annie Besant Road

Prabhadevi, Bombay-400025

INDIA

JBF Scientific Corportion

2 Jewel Drive

Wilmington, MA 01887

Attn: E. E. Johanson

Dr. Gary L. Johnson, P.E.

Electrical Engineering

Kansds state University

Manhattan, KS 66506

J. P. Johnston

Stanford University

Department of Mechanical Eng

stanford, CA 94305

B. O. Kaddy, Jr.

Box 353

31 Union Street

$\mathrm{Hillsboro,} \mathrm{NH} \quad 03244$

Kaman Aerospace Corporation

Old Windsor Road

Bloomfield, CT 06002

Attn: w. Batesol

Robert E. Kelland

The College of Trades and Tech

P.O. Box 1693

Prince Philip Drive

st. John's, Newfoundland

CANADA AIC 5 P7

Larry Kinnett

P.O. Box 6593

Santa Barbara, CA 93111

O. Krauss

Michigan State University

Division of Engineering Res

East Lansing, NiI 48824

Lawrence Livermore Lab

P.O. Box $808 \quad L-340$

Livermore, CA 94550

Attn: D. W. Dorn 
M. Lechner

Public Service Company of NM P.O. Box 2267

Albuquerque, NM 87103

George E. Lennox

Industry Director

Mill Products Division

Reynolds Metals Company

6601 west Broad street

Richmond, VA 23261

J. Lerner

State Energy Commission

Research and Development Div

1111 Howe Avenue

Sacramento, CA 95825

L. Liljidahl

Building 303

Agriculture Research Center

USDA

Beltsville, MD 20705

P. B. S. Lissaman

Aeroenvironment, Inc.

660 South Arroyo Parkway

Pasadena, CA. 91105

Olle Ljungstrom

FFA, The Aeronautical Research

Box 11021

S-16111 Bromma

SWEDEN

Los Alamos Scientific Lab

P.O. Box 1663

Los Alamos, NM 87544

Attn: J. D. Balcomb Q-DO-T

Library

Ernel L. Luther

Senior Associate

PRC Energy Analysis Co.

7600 Old Springhouse Rd.

McLean, VA 22101

L. H. J. Maile

48 York Mills Rd.

Willowdale, Ontar io

CANADA M2P LB4
Jacques R. Maroni

Ford Motor Company

Environmental Research and Energy

Planning Director

Environmental and Safety Eng

The American Road

Dearborn, MI 48121

Frank Matanzo

Dardalen Associates

15110 Frederick Road

Woodbine, MD 21797

H. S. Matsuda, Manager

Composite Materials Laboratory

Pioneering R\&D Laboratories

Toray Industries, Inc.

Sonoyama, Otsu, shiga

JAPAN 520

J. R. McConnell

Tumac Industries, Inc.

650 Ford st.

Colorado Springs, CO 80915

James Meiggs

Kaman Sciences Corporation

P.O. Box 7463

Colorado Springs, co 80933

R. N. Meroney

Colorado State University

Department of Civil Engineering

Fort Collins, Co 80521

G. N. Monsson

Department of Economic Planning and Development

Barrett Building

Cheyenne, WY 82002

NASA Lewis Research Center (2)

21000 Brookpark Road

Cleveland; OH 44135

Attn: J. Savino

R. L. Thomas

W. Robbins

K. Kaza

$V$, Nelson

West Texas State University

Department of Physics

P.O. Box 248

Canyon, TX 79016 
Leander Nichols

Natural Power, Inc.

New Boston, NH 03070

Oklahoma State University

Stillwater, OK 76074

Attn: W. I. Hughes

EE Department

D. K. McLaughlin

ME Department

Oregon State University (2)

Corvallis, OR 97331

Attn: R. E. Wilson ME Department

R. W. Thresher

ME Department

Pat F, O'Rourke

Precinct 4

County commissioner

City-County Building

El Paso, TX 79901

H. H. Paalman

Dow Chemical USA

Research Center

2800 Mitchell Drive

Walnut Creek, CA 94598

R. A. Parmelee

Northwestern University

Department of Civil Eng

Evanston, IL 60201

Helge Petersen

Riso National Laboratory

LK-4000 Roskilde

DENMARK

Wilson Prichett, III

National Rural Electric Coop

Association

1800 Massachusetts Avenue NW

Washington, DC 20036

Dr. Barry Rawlings, Chief

Division of Mechanical Eng

Commonwealth Scientific and Ind

Research Organization

Graham Road, Highett

Victoria, 3190

AISTRALIA
Thomas w. Reddoch

Associate professor

Department of Electrical Engineering The University of Tennessee

Knoxville, TN 37916

A. Robb

Memorial University of Newfoundland

Faculty of Engineering and Applied Sci

St. John's Newfoundland

CANADA AlC $5 \mathrm{~S} 7$

Dr.-Ing. Hans Ruscheweyh

Institut fur Leichtbau

Technische Hochschule Aachen.

wullneratrasse 7

GERMANY

Gwen Schreiner

Librarian

National Atomic Museum

Albuquerque, NM 87185

Arnan Seginer

Professor of Aerodynamics

Technion-Israel Institute of

Technology

Department of Aeronautical

Enqineering

Haifa, ISRAEL

Dr. Horst Selzer

Dipl.-Phys.

Wehrtechnik und Energieforschung

ERNO-Raumfahrttechnik GmbH

Hunefeldstr . 1-5

Postfach $10 \quad 59 \quad 09$

2800 Bremen 1

GERMANY

H. Sevier

Rocket and Space Division

Bristol Aerospace Ltd.

P.O. Eox 874

Winnipeg, Manitoba

CANADA R3C 2S4

P. N. Shankar

Aerodynamics Division

National Aeronautical Laboratory

Bangalore 560017

INDIA 
David Sharpe

Kingston Polytechnic .

Canbury Park Road

Kingston, surrey

UNITED KINGDOM

D. G. Shepherd

Cornell university

Sibley School of Mechanical and Aerospace Engineering

Ithaca, NY 14853

H. P. Sleeper

Kentin International

2000 Birdspring Road

Huntsville, AL 35802

Dr. Fred Smith

Mechanical Engineering Depart

Colorado State University

Ft. Collins, CO 80521

Kent Smith

Instituto Technologico Costa Rica Apartado 159 Cartago

COSTA RICA

Leo H. Soderholm

Iowa State University

Agricultural Engineering

Ames, IA 50010

Southwest Research Institute (2)

P.O. Drawer 28501

San Antonio, TX 78284

Attn: W. L. Donaldson

R. K. Swanson

Rick stevenson

Route 2

Box 85

Springfield, MO 65802

Dale T. stjernholm, P.E. Mechanical Design Engineer

Morey/Stjernholm and Associates

1050 Magnolia Street

Colorado Springs, CO 80907 .

G. W. Stricker

383 Van Gordon 30-559

T.akewood, CO 80228
C. J. Swet

Route 4

Box 358

Mt. Airy, MD 21771

R. J . Templin (3)

Low Speed Aerodynamics Section

NRC-National Aeronautical Establishment

Ottawa 7, Ontario

CANADA KIA OR6

Texas Tech University (3)

P.O. BOX 4289

Lubbock, TX 79409

Attn: K. C. Mehta, CE Department

J. Strickland, ME Department

J. Lawrence, ME Department

Fred Thompson

Atari, Inc.

155 Moffett Park Drive

Sunnyvale, CA 94086

J. M. Turner, Group Leader

Terrestrial Energy Technology program off Energy Conversion Branch

Aerospace Power Division

Aero propulsion Laboratory

Department of the Air Force

Air Force Wright Aeronautical Laboratories

Wright-Patterson Air Force Base, OH 45433

United Engineers and Constructors, Inc.

Advanced Engineering Department

30 South 17 th Street

Philadelphia, PA 19101

Attn: A. J. Karalis

University of New Mexico (2)

New Mexico Engineering Research Inst

Campus P.O. Box 25

Albuquerque, NM 87131

Attn: D. E. Calhoun

G. G. Leigh

University of New Mexico

Albuquerque, NM 87106

Attn: K. T. Feldman

Energy Research Center

V. Sloglund

ME Lepartment 
Jan Vacek

Eolienne experimentale C.P. 279, Cap-aux-Meules

Iles de la Madeleine, Quebec CANADA

Irwin E. Vas

Solar Energy Research Inst

1617 cole Blva.

Golden, $C O \cdot 80401$

Otto de Vries

Nationall Aerospace Lab

Anthony Fokkerweg 2 .

Amsterdam 1017

THF NETHERLANDS

R. Walters

West Virginia University

Department of Aero Eng

1062 Kountz Avenue

Morgantown, WV 26505

E. J. Warchol

Bonneville Power Admin

P.O. Box 3621

Portland, OR 97225

D. F. Warne, Manager

E'nergy and Power "Systems

ERA Ltd.

Cleeve Rỏ.

Leatherhead

Surrey KT22 7SA

ENGLAND

R. A. Watson

Stanford University

546B Crothers Memorial Hall

stanford, CA 94305

R. J. Watson

Watson Bowman Associates, Inc. $1280 \mathrm{Niagara}$ Et.

Buffalo, NY 14213

R. G. Watts

Tulane University

Department of Mechanical Eng

New Orleans, LA 70018
Pat We is

Solar Energy Research Inst

1637 Cole Blvd.

Golden, CO 80401

W. G. Wells, P.E.

Associate Professor

Mechanical Engineering Depart

Mississippi State University

Mississippi State, MS 39762

T. Wentink, Jr.

University of Alaska

Geophysical Instilute

Fairbanks, AK 99701

West Texas State University

Government Depository Library Number 613

Canyon, TX 79015

Wind Enerqy Report

Box 14

$104 \mathrm{~S}$. Village Ave.

Rockville Centre, NY 11571

Attn: Farrell smith seiler

Richard E. Wong

Assistant Director

Central solar Enargy Resedich

Corporation

$1200 \mathrm{sixth}$ street

328 Executive Plaza

Detroit, MI 48226

1000 G. A. Fowler

1200 I. D. Smith

3141 T. L. Werner (5)

3151 W. L. Garner (3)

For DOE/TIC (Unlimited Rel)

3161 J. E. Mitchell (15)

3161 P. S. Wilson

4533 J. W. Reed

$4700 \mathrm{~J} . \mathrm{H}$. Scott

4710 G. E. Brandvold

4715 R. H. Braasch (100)

4715 J. D. Cyrus

4715 R. D. Grover

4715 E. G. Kadlec

4715 P. C. Klimas

4715. M. T. Mattison

4715 R. O. Nellums

4715 W. N. Sullivan

$4715 \mathrm{M}$. H. Worstell 
5500 O. E. Jones

5510 D. B. Hayes

5520 T. B. Lane

5523. R. C. Reuter, Jr. (15)

5523 D. B. Clauss

5523 T. G. Carne

5523 J. R. Koteras

5523 D. W. Lobitz

5523 D. A. Popelka

5523 P. S.' Veers

5530 W. Herrmann

560.0 D. B. Schuster

5620 M. M. Newsom

5630 R. C. Maydew

5632 C. W. Peterson.

5633 . S. McAlees, Jr.

5633 R. E. Sheldahl

8266 E. A. Aas

DOE/TIC (25)

(R. P. Campbe1.1, 3172-3) 


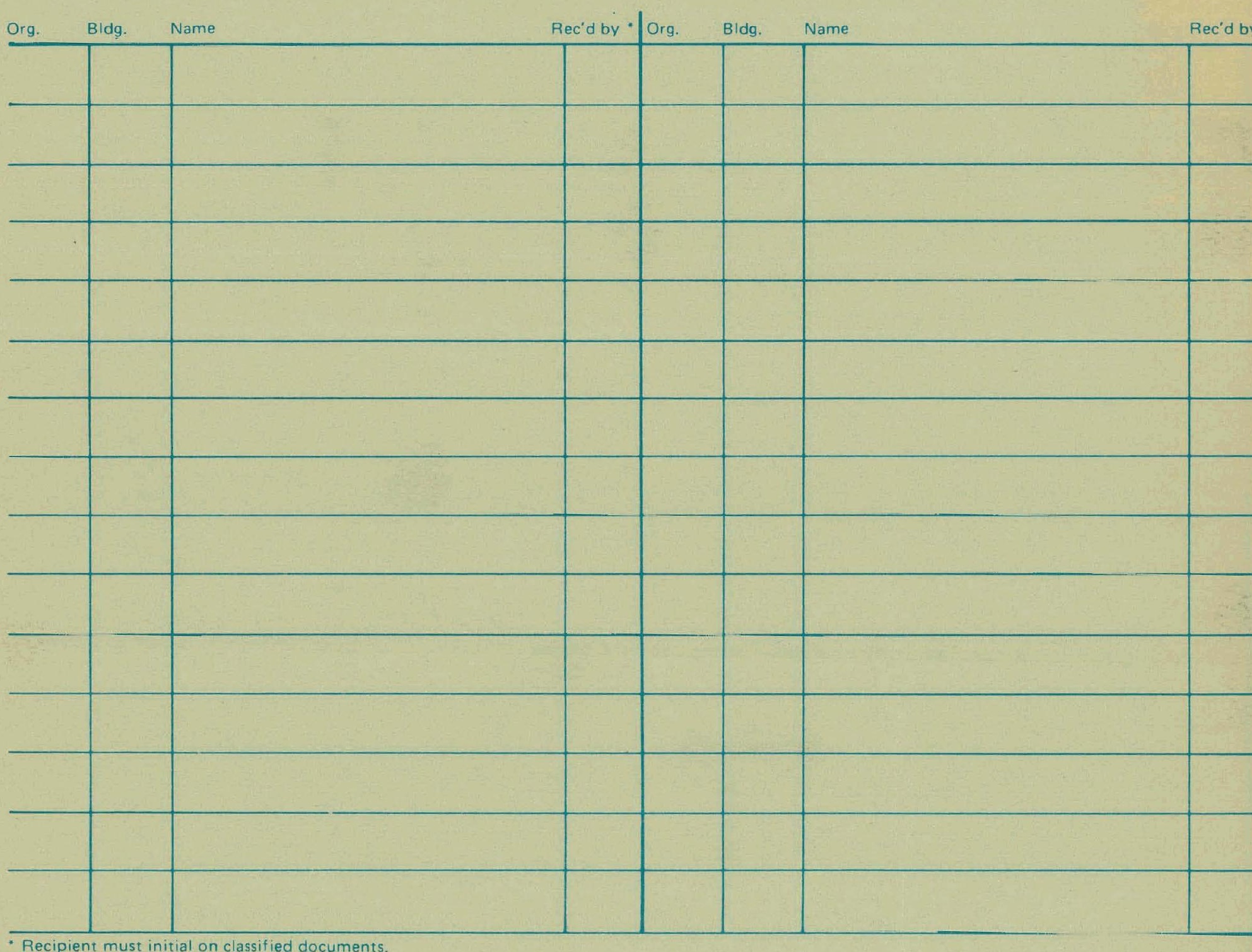

- Recipient must initial on classified documents. 